\title{
Robert Miller
}

\section{I came, I saw, I researched \\ Students reflect on library life in six-word memoirs}

A

University of Maryland University Colege (UMUC), I teach LIBS 150, an online, required one-credit library skills course for undergraduates. As an extra-credit assignment near the end of the seven-week class, I ask students to write a six-word memoir about their library, reading, or research experiences. Having undergone the educational rigors of the LIBS 150 information literacy boot camp-database selection, Boolean searching, source evaluation, formatting citations, and other research skills—students appreciate the chance to earn an extra point toward their course grade with a fun, fast assignment that helps them reflect on life as a library user and academic researcher.

The six-word memoir became an Internet and publishing phenomenon at the SMITH Magazine Web site. ${ }^{1}$ The rules are simple: write about your life in six words. The genre was inspired by Hemingway's ability to invoke an entire tragic tale in just six words: "For sale: baby shoes, never worn." Subsequent six-word memoirs tend to be lighter, such as the signature six-worder of SMITH founder Larry Smith: "Big hair, big heart, big hurry." The mini-memoir made the jump from online to print with a cottage industry of books by Smith and coauthor Rachel Fershleiser, including Not Quite What $I$ Was Planning: Six-Word Memoirs by Writers Famous and Obscure ${ }^{2}$ and I Can't Keep My Own Secrets: Six-Word Memoirs by Teens Famous \& Obscure. ${ }^{3}$

The six-word memoir lends itself to classroom use. "I know teachers all around the country, really, the world," Smith has noted, "have used it all over, in grade schools, kindergarten, grad school." ${ }^{3}$ Community-college English professor John Yohe, for example, has his students create six-word memoirs and comment on them in small groups. ${ }^{5}$ That ice-breaking exercise builds a sense of community in the class while introducing students to the idea of writing within a genre and conducting peer review.

To introduce my students to the six-word memoir and convey my expectations for the extra-credit assignment, I posted the following in our online class:

\section{Six-word library memoir}

The six-word memoir is a Web phenomenon and book publishing phenomenon. National Public Radio ran a story about it: http://www.npr. org/templates/story/story.php?storyId $=18768430$. The official Six Word Web site is www.smithmag.net/sixwords.

The Six-Word Memoir works like this: people write a real-life story in exactly six words. Here are a few examples from the SMITH Web site:

- Not quite what I was planning.

- Fifteen years since last professional haircut.

- Never really finished anything except cake.

For your extra-credit assignment, write a six-word library memoir and post it in this discussion thread: convey in exactly six words a library or reading

Robert Miller is reference and instruction librarian, information and library services at the University of Maryland University College, e-mail: rmmiller@umuc. edu

๑) 2011 Robert Miller 
or research experience. Here are a few examples:

- Wish this article were full-text.

- Contented quiet hours among beautiful books.

- What happened to the card catalog?

This is meant to be a fun, easy way to earn an extra point. Everyone who writes a six-word library memoir will get the extra credit (your memoir doesn't have to sound like it was written by Ernest Hemingway or anything). So have fun, don't feel like you have to spend a long time on this, and by all means, if you want to express frustration about using the library, I am completely open to that. I want to read six-word memoirs that reflect all types of library or reading or research experiences, not just the perfectly happy ones.

\section{Student reflections}

If the success of an assignment can be measured by the enjoyment the instructor derives from reading students' submissions, then this assignment was a smash hit. I found myself literally laughing out loud and replying with heartfelt smiley-faces to six-word library memoirs such as:

- Must bend databases to my will.

That memoir cleverly adopts the idiom of an imperiled comic-book superhero to express important affective aspects of the research process: the student has obviously felt frustration in her use of the library, while persevering to achieve a research goal. That student, who also wrote that she was familiar with the six-word genre and had enjoyed writing in it before, was able to speak to a common experience of library users with heartening humor.

Other students wrote in a similar vein, frankly addressing the problems and sense of discouragement that all researchers have felt:
- Would pay for a researching robot.

- Every book I need is unavailable!

- Researching can be a little complicated.

The burdensome and antiquated tradition of properly citing sources-the bane of every beginning researcher-came in for its share of abuse:

- Citations can be difficult at times

- I find professors grade citations differently

- Citations are annoying but necessary requirements

Students did, however, report on acquiring citation skills, as well as newfound confidence conducting research in general:

- Finally, I know how to cite!

- Good key terms, great search results.

- Confident about using the online library.

- Didn't understand library until LIBS course.

- This old dog learned new tricks.

One of my favorite memoirs concerns a challenge that academic librarians commonly face, raising the library's visibility on campus:

- Really, my school has a library?

If an information literacy class does nothing else than make students aware that their school does in fact have a library, the class has succeeded.

Some students used their six-word memoir to comment on the class itself. This student spoke of the unexpected rigor of our onecredit class, which, as the instructor, I take as a compliment:

- One credit course, three credit research.

LIBS 150 is a required course for all undergraduates, and several students breathed a sigh of relief in their memoirs:

- Finally, checked off my requirements list. 
- One class closer to my dream.

I find the word dream in that last memoir especially evocative. Most UMUC students are adult learners, many of whom have families and work full-time, and simply were not able to obtain a college degree at the traditional age, in their early 20s. For that reason, I fully understand students approaching my or any course with the attitude, "I've got to get this done." Successfully completing my class does bring a student one step closer to the dream of graduation; in the case of an adult learner, it is a dream they may have contemplated for many years.

Because my students are adult learners, with a wealth of life experience, I didn't mind if one or two of them strayed from the narrow path of the assignment and wrote life, rather than library, memoirs. When one student wrote in six words that he was going to become a dad again, I and others in the class congratulated him, and of course he received the one-point extra credit.

Several students marked the historic shift we are seeing in reading technology, voicing positive and negative opinions on e-books:

- Still love to read paper books!

- Is the Kindle version available yet?

Other students directed their attentionarchly-to libraries themselves:

- Libraries are excellent places for sleeping.

- Wish my library had a PS3.

Even if a librarian cannot provide public access to the latest Sony PlayStation, students still express affection for the profession as a whole:

- Never met a librarian I disliked.

And one student offered librarians implicit advice on creating an exciting, glamorous physical environment for patrons. He had the opportunity to visit the sleek, modern
Amsterdam Public Library in the Netherlands and wrote:

- This looks like an Apple store.

There could be no higher praise coming from that student, an inveterate Mac user.

Finally, one student summed up not only what it is like to conduct research online-she was able to give voice to the entirety of our Web-driven Zeitgeist:

- Every link leads to another link.

The memoirs were posted in a discussion thread, and, though it was not a requirement of the assignment, many students took the time to respond to their classmates' posts, seconding them, laughing, and cheering each other on. The exercise worked well in an asynchronous online class—students had time to reflect on their library experiences, select just the right six words, and also read and comment on their classmates' memoirs.

The assignment worked particularly well towards the end of the term, as a fast, enjoyable way for students to earn extra credit when they were busy completing course modules and doing an in-depth research exercise. The six-word library memoir encourages students to think critically-and sometimes acerbically_on their experiences as library users and academic researchers. The freedom to share a range of thoughts and emotions about libraries and research-from achievement to puzzlement to frustration-can further the feeling of the class "being in this together," which is especially helpful in an online class, where a sense of presence and community is essential.

\section{Notes}

1. The official Six-Word Memoir Web site is at www.smithmag.net/sixwords.

2. Larry Smith and Rachel Fershleiser, Not Quite What I Was Planning: Six-Word Memoirs by Writers Famous and Obscure (New York: Harper, 2008).

(continues on page 356) 
compass instead of a map, navigating the information landscape becomes a process of sensemaking.

Whether we think of the information landscape as a physical or a virtual space, a map is useful only if we try to cross a region that has been charted by someone and remains relatively permanent in patterns of organization.

For example, if a student is looking for materials on the history of 19th-century Illinois or biographical information on Barbara Kingsolver, the process is relatively easy because those topics parallel information organization in libraries. However, if a student wants materials about cultural forces in the interplay between fundamental Christians and fundamental Muslims in social networks, much of relevant information will be on the Web where it sometimes unknowable and often unpredictable. In such a wilderness, there is no detailed map to guide our every step. In helping our students, we have to use a compass, guided by the lay of the land which forms the context.

In the present environment of continuous change, many times with local constraints or needs, it becomes relatively hard to even follow a path that another library or person has charted because that path may no longer exist after the most recent storm.

So we need to proceed by our knowledge of general landscape features and patterns of information organization. This knowledge may be tacit that we acquire through experience. Sometimes we go in an apparently straight line only to find that we are on a cliff. But it is only from that vantage point we get an overview of how to cross a river or a ravine. Then our back-tracking becomes purposeful. We are not wandering in the wilderness. Instead we become improvisational in establishing a strategy to cross the next obstacle. Sometimes it is easier to just sit and wait out the next storm before continuing. This is where we have to use a compass, our knowledge base, and our experiences to improvise a strategy for moving forward in the information landscape. Even if a path has been charted, it is only good before the next growing season, the next storm, or even the next day.

In the manicured garden, we use maps. Our aim is to find the most effective and efficient path to reach a known objective. In the wilderness, we must use a compass to set directions, rely on our understanding of information organization and patterns to craft possible paths, and use our knowledge to recognize when we have found what we are seeking. This is when we look for efficacious search strategies and satisficing solutions. We show the students a direction and give them rules of thumb established through our experience so that they may have a very good chance of finding what they need.

\section{Notes}

1. "Musings on the 2006 IACRL Conference," IACRL Newsletter 29 (Fall 2006): 1, 10, 12. Available online at http://iacrl.net /Newsletters/2006fall.pdf.

2. The Future of Leadership: Today's Top Leadership Thinkers Speak to Tomorrow's Leaders, eds. Warren Bennis, Gretchen M. Spreitzer, and Thomas G. Cummings (San Francisco: Jossey-Bass, 2001), 91-102.

3. Ibid., 92. $n$

("I came, I saw, I researched," cont. from page 340)

3. Larry Smith and Rachel Fershleiser, $I$ Can't Keep My Own Secrets: Six-Word Memoirs by Teens Famous \& Obscure (New York: HarperTeen, 2009).

4. Nancy Stetson, "Six Words, One Idea, Intriguing Challenge: Mini-Memoirs Summarize a Life," Fort Myers Florida Weekly, June 18, 2008, accessed March 12, 2011, http:// fortmyers.floridaweekly.com/news/2008-0618/arts_ent/061.html.

5. John, Yohe, "Using Six-Word Memoirs as an Icebreaker and Introduction to the Writing Process," Teaching English in the Two Year College 38, no. 1 (September 2010): 80-81. n 